\title{
Efficient Data Assumption and Optimization of Analog Response Communication Systems
}

\author{
N. Prasanna Moorthi ${ }^{1}$, V. Mathivanan ${ }^{2}$ \\ ${ }^{1}$ Research Scholar, Department of Information Technology, AMET University, Chennai \\ ${ }^{2}$ Department of Computer Science, ARM college of Engineering and Technology, Chennai
}

\begin{tabular}{l} 
Article Info \\
\hline Article history: \\
Received Oct 13, 2017 \\
Revised Dec 17, 2017 \\
Accepted Jan 3, 2018 \\
\hline
\end{tabular}

Keywords:

\section{AFCS}

Data Transmission

DCS

MSE

Speed Winding

\begin{abstract}
This paper is focused on the examination of connection between the premier remote reason exactitude of transmission information and qualities for driving edge correspondence structures and straightforward data cesium (AFCS) identified with transmission of signs from fundamental sources. It's displayed that the mean sq. oversight of transmission picks information properties of AFCS. Varieties between the cutoff purposes of AFCS thought of as summed up correspondence channel and their forward channel square measure investigated. The new impacts appearing in incredible AFCS and in DCS working near Shannon's cutoff square measure thought of also. Amid this works advanced and essential correspondence frameworks were thought of with none inclinations and no confirmation that the use of simple cesium is frequently less able than modernized correspondence structures had been given start inside the no in this way far off past. The secured comes about unambiguously showed the capacity of simple data cesium to transmit the signs while not committal to composing with to a little degree rate up to the uttermost ranges of the forward control.
\end{abstract}

Copyright () 2018 Institute of Advanced Engineering and Science. All rights reserved.

\section{Corresponding Author:}

N. Prasanna Moorthi,

Research Scholar, Department of Information Technology,

AMET University,

Chennai.

\section{INTRODUCTION}

In the movement of flexible information estimation structures displayed that information properties of amazing AFES satisfy the preeminent remote reason respects, and organize of the overhaul endeavor connects with the framework format. Use of the approach made into AFCS approved North American nation to exhaust bothers that blocked execution of the results of prior investigation [1].

The decided social affairs of affiliations collaborate a system of superb AFCS transmission the signs with irrelevant mean sq. mess up. it had been produced that superb AFCS transmit the signs over a forward channel with the bit rate venerate its ability and power and information trade restrain efficiencies of transmission end to such an level [2]-[4].

Additionally, they got affiliations interface these qualities with the parameters of the structures and condition of utilization. The postponed outcomes of cutting edge examination of late impacts and components affecting the standard, piece rate, and ampleness of transmission show that AFCS theory could be a fundamentally untouched field for enable hypothetical and related consider [5].

This objective of this paper is to isolate connection between MSE of transmission and information attributes of AFCS and DCS utilized for essential signs transmission [6]. The varieties between the limits of AFCS and their forward channels square measure thought of. it's demonstrated that the speed winding breaking point is particularly associated with the reason for restriction of AFCS [7]. The examination is gone 
before by a meeting of the clarifications of insignificance of past investigation in AFCS and routes that to change clear them. The acquainted with results will be utilized with the remote sensors plan [8].

\section{RESEARCH METHOD}

From a general perspective, every DCS and AFCS utilized for transmission of dependable signs could be an information passing on channel of remote estimation frameworks or, all the a ton for goodness' sake thought of, of estimation structures. An essential supply makes flag whose cases square measure passed on by AFCS or DCS to the recipient as evaluations their qualities. These assessments recuperate the begin organize development with bungles caused by clamors acting inside the transmission channels.

In science, estimation, and administration hypothesis, the basic live of the exactitude of evaluations is MSE or difference of examinations. This is a reasonable and quantitative establishment of the framework's execution reason by reason in context of intelligent models of the structure's fundamental areas.

\section{RESULTS AND ANALYSIS}

It is essential that nowadays, information attributes of estimation, control, or estimation structures cause no uncommon intrigue. amid this way, execution of DCS is assessed by information qualities however not by MSE uninhibitedly from the solid or pushed signs transmitted. As in, MSE of the transmission is that the essential foundation of AFCS execution.

\section{CONCLUSION}

They indicated includes realization show that MSE is that the focal execution perspective of AFCS execution and perfect AFCS transmit signals with restrain exactitude, bit rate, and P-B efficiencies. Input rattle causes declination of AFCS information qualities from limits. This outcome should in like way appear in DCS, whose execution approaches these limits. They indicated transmission-gathering calculation grants outlining P-B supportive channels for remote sensors. In any case, these equations square measure gotten as consequences of reduction of the MSE of transmission, by and by not on account of the impossible of the live of fundamental information on the game orchestrate of past spreads.

\section{REFERENCES}

[1] Omura J. K., "Most favorable transmission of analog data for channels with feedback," IEEE Trans. on Inf. Theory, vol/issue: 14(1), pp. 38-43, 1968.

[2] Gallager R. G., "Information theory and reliable communication," New York: Wiley, pp. 2, 1968.

[3] Platonov A., "Capacity and power-bandwidth efficiency of wireless adaptive feedback communication systems," IEEE Communications Letters, vol/issue: 16(5), pp. 573-576, 2012.

[4] Platonov A., "An Optimal identification of regression-type processes under adaptively controlled observations," IEEE Transactions on Signal Processing, vol/issue: 42(9), pp. 2280-2291, 1994.

[5] Platonov A., "Analytical methods of analog-digital adaptive estimation systems design," Warsaw, Publishing House Warsaw Univ. of Techn., series Electronics, pp. 154, 2006.

[6] Johnson T. and Singh S. K., "Fuzzy C strange points clustering algorithm," International Conference in Information Communication and Embedded Systems (ICICES), pp. 1-5, 2016.

[7] Tiwari P., et al., "Malware detection in android application by rigorous analysis of decompiled source code," International Conference in Computing Communication Control and automation (ICCUBEA), pp. 1-6, 2016.

[8] N. Armi, et al., "Malicious User Attack in Cognitive Radio Networks," TELKOMNIKA (Telecommunication Computing Electronics and Control), vol/issue: 15(3), 2017. 